\title{
REVISIÓN: USO DE EXTRACTOS VEGETALES EN EL MANEJO INTEGRADO DE PLAGAS, ENFERMEDADES Y ARVENSES.
}

\author{
REVIEW: PLANT EXTRACTS USED AS BIOCONTROL IN \\ MANAGEMENT OF PLAGUES, DISEASES AND WEEDS.
}

\author{
Alvaro Celis ${ }^{1}$, Cristina Mendoza F. 1 y Marco Eduardo Pachón1. \\ Recibido para evaluación: Noviembre 5 de 2008 - Aceptado para publicación: Mayo 13 de 2009
}

\section{RESUMEN}

La presente revisión recopila diversos casos reportados en la literatura sobre la actividad biológica de extractos y metabolitos de origen vegetal y hongos para el control de insectos, enfermedades y arvenses en el sector agrícola. La finalidad es dar a conocer formas alternativas de control de problemas fitosanitarios dentro de una agricultura con menor impacto ambiental.

Palabras claves: actividad biológica, metabolitos secundarios, control biológico.

\begin{abstract}
The present review compiles sorne reported cases in scientific papers about biological activity of plant extracts, metabolites and fungi on insect, disease and weed control in agriculture. The purpose is to present alternative ways to control phytosanitary problems within agriculture with lower environmental impact.
\end{abstract}

Keywords: biological activity, secondary metabolites, biological control.

'Universidad de Cundinamarca, Oficina de Investigación, Diagonal 18 No. 20 -29, Fusagasugá.

Tel: 8732512 Ext. 134. email: acelisforero@yahoo.es; cmendozaf@yahoo.com; pachon10@gmail.com 


\section{INTRODUCCIÓN}

El empleo de extractos vegetales para el control de plagas, enfermedades y arvenses en el marco de una agricultura sostenible constituye una alternativa promisoria, debido a su efectividad, bajo costo y no ser contaminantes del ambiente. Alrededor de 3.000 compuestos naturales de origen vegetal han sido reportados mostrando actividad bactericida, fungicida, insecticida, repelente y nematicida (Regnault, 2004; Obledo et al., 2004; Kagale et al., 2004). Las plantas y sus derivados han mostrado efectos controladores contra ácaros, roedores, nemátodos, bacterias, virus, hongos e insectos (Grainge y Ahmeds, 1988).

Los extractos de origen vegetal han sido utilizados desde la antigüedad por los hindúes, chinos, griegos y romanos con fines rodenticidas, insecticidas y conservación de víveres almacenados. Durante muchos siglos, las formulaciones basadas en las plantas se utilizaron para combatir los insectos plaga. En el siglo XIX se utilizaban como fitosanitarios moléculas de origen vegetal como los alcaloides. A partir de la segunda guerra mundial esta primera generación de fitosanitarios de origen vegetal, fueron sustituidos por pesticidas de síntesis química como el DDT, organoclorados, organofosforados y carbamatos. En las últimas dos décadas, se han intensificado los estudios de productos de origen vegetal en su parte química, con énfasis en los metabolitos secundarios, los cuales están implicados en el control biológico contra patógenos o plagas, y en ciertos casos activando procesos de defensa en la planta y brindando una protección preventiva (Kagale et al., 2004).

Los extractos de origen vegetal se caracterizan por la presencia de determinados metabolitos secundarios los cuales forman parte de las estrategias defensivas de las plantas, y que pueden ser agrupados en compuestos nitrogenados, fenólicos y terpenoides. Dichos compuestos le proporcionan importantes características a los extractos, como son antialimentarios, antivirales, antimicrobianos, repelentes, inhibidores de germinación de semillas que permiten su utilización para proteger los cultivos e incrementar la calidad y su producción alimentaría, ya que tienen la propiedad de ser menos tóxicos y más fácilmente degradables (Philogenet et al., 2004). A continuación se presenta una revisión detallada sobre el uso de extractos vegetales para el control de plagas, enfermedades y arvenses, que pueda servir como documento de consulta dentro de un Manejo Integrado de Plagas, Enfermedades y Arvenses (MIPEA). Esta revisión se realiza dentro del marco del proyecto "Manejo Integrado de plagas, enfermedades y arvenses en albahaca (Ocinum basilicum), menta (Mentha spicata) y estevia (Stevia rebaudiana) bajo tres condiciones ambientales en Colombia" cofinanciado por el Ministerio de Agricultura y Desarrollo Rural y ejecutado en alianza por la Universidad Nacional de Colombia, la Universidad de Córdoba y la Universidad de Cundinamarca.

\section{CONTROL DE ARVENSES}

Las pérdidas ocasionadas por la competencia de arvenses en cultivos además de reducir los rendimientos, disminuye notoriamente la calidad de los productos incidiendo directamente sobre los precios. Las pérdidas anuales causadas por las malezas en la agricultura de los países en desarrollo han sido estimadas en el orden de 125 millones de toneladas de alimentos, cantidad suficiente para alimentar 250 millones de personas. Adicionalmente se ha demostrado que las malezas generan un efecto depresivo sobre los cultivos, limitando el normal desarrollo y posterior producción en una explotación comercial; se ha comprobado que por el mal manejo de éstas se puede llegar a perder hasta el $100 \%$ de las producciones, poniendo en riesgo la seguridad alimentaria de los pueblos (Labrada, 2003).

Tradicionalmente el control de estas especies se ha efectuado por métodos convencionales como manual, mecánico y químico. Los dos primeros se han utilizado principalmente para cultivos de pequeña extensión y el último mayormente empleado en la agricultura tecnificada, ocasionando costos altos, resistencia de malezas a herbicidas y contaminación ambiental. Entre las alternativas para el manejo de arvenses se encuentran el control biológico y el uso de extractos vegetales (Celis eta!., 2008). 
El control biológico puede definirse como eluso de organismos vivos para el control de arvensesplagas. Los enemigos naturales utilizados para el control de las arvenses son aquellos mismos que las atacan, ya sea ingiriendo su masa vegetal por este agente liberado o por enfermedades de las plantas, particularmente hongos. Los patógenos de las plantas son los que ofrecen las mejores opciones para el control biológico aumentativo, ya que algunos patógenos pueden producirse masivamente a bajo costo por vía de fermentación a escala industrial y ser vendidos como micoplaguicidas (Cock, 1986). Las ventajas de este control son amplias, no necesita de esfuerzos manuales excesivos, evita la contaminación del medio ambiente, no altera el equilibrio biológico. Para implementarse debe realizarse previamente un estudio minucioso y experimental del agente a introducir o multiplicar, es decir, requiere de un alto grado de desarrollo científico-técnico, lo cual limita su empleo, solo debe ser utilizado contra especies agresivas o dañinas con perspectivas de ser eliminadas, implica grandes riesgos y nunca existe la absoluta garantía de la eficiencia de sus resultados, aunque se han obtenido experiencias positivas sobre la erradicación o control de varias plagas y arvenses (Catasús, 1997). Las toxinas de los microorganismos ofrecen posibilidades potenciales en la lucha contra malezas por la obtención de nuevas moléculas de herbicidas. En algunos laboratorios se han aislado e identificado diferentes toxinas producidas por los patógenos para establecer la estructura molecular y luego ser utilizadas en la industria de herbicidas. El primer producto microbiano que fue comercializado directamente como herbicida fue Bialafos que se obtiene por la fermentación de Streptomyces viridochromogenes (Díaz y Pérez, 2005).

En cuanto al uso de extractos vegetales, se ha reportado que los extractos de ciertas plantas, al igual que los residuos de alguna de ellas en el suelo, ejercen un efecto inhibitorio sobre las plántulas de diferentes especies cultivadas, lo que se ha denominado alelopatía. Esta se refiere a la inhibición del desarrollo de una planta por acción de sustancias químicas liberadas por otra especie vegetal (Putnam, 1985). Los inhibidores químicos producidos por los agentes alelopáticos reciben el nombre de metabolitos secundarios y pertenecen a varias clases de compuestos tales como fenoles, aldehídos, cumarinas, glucósidos, terpenos y cianinas orgánicas (Rice, 1984). La actividad alelopática y tipos de metabolitos presentes en el follaje de Lantana trifolia L., fueron estudiados por Valerino et al. (2005) con el fin de obtener compuestos puros potencialmente activos, a partir de extractos de plantas con actividad alelopática contra malezas. Se determinó la actividad alelopática en condiciones de laboratorio de extractos de nhexano y etanol, evaluándose los índices de vigor y reducción de plántulas de pepino, tomate y trigo frente a dichos extractos. Se observó que ambas fracciones redujeron el crecimiento de la raíz y el coleóptilo, estando más marcado este efecto en el extracto etanólico. En L. trifolia se detectó la presencia de triterpenos/esteroides y flavonoides en el extracto clorofórmico y triterpenos/esteroides, flavonoides y glicósidos en el extracto de n-butanol. En ambos extractos se determinaron las concentraciones mínimas inhibitorias frente a las plántulas estudiadas.

Al evaluar el potencial alelopático de lavados foliares provenientes de Echinochloa colona sobre el porcentaje de germinación y longitud radical de las especies cultivadas Allium cepa, Cucumis sativus, Lactuca sativa, Lycopersicum esculentum y Oryza sativa. Miquilena y Lazo (2005) encontraron que la especie L. esculentum mostró el mayor incremento de la longitud radical por aplicación de los lavados de hojas de E. colona a los 15 días después de germinación. En A. cepa se apreciaron efectos estimulatorios significativos del crecimiento radical por aplicación de los lavados foliares. Los resultados indican que los tratamientos aplicados ejercen un potencial efecto alelopático de carácter estimulatorio sobre L. esculentum y A. cepa en función de la edad de los extractos provenientes de la planta donadora. Alfonso et al. (2005) estudiaron el efecto alelopático de extractos acuosos de Nerium oleander, Aleuritis fordii, Ocimun sanctum, Gliricidia sepium y Thevetia peruviana sobre la germinación de semillas y desarrollo del eje radículo-hipocotilar en cinco especies de malezas. Todos los extractos evidenciaron efectos inhibitorios y los metabolitos secundarios más frecuentes fueron triterpenos, fenolesy flavonoides. 
Robayo y Rodríguez (2006) evaluaron el efecto alelopático de tres dosis de extractos etanólicos de Swinglia glutinosa y Piper aduncum sobre semillas de cinco arvenses asociadas a cultivos de clima cálido (Rotboelia cochinchinensis, Echinocloa colona, Senna obtusifolia, Ipomea tiliacea y Leptochloa filiformis). Los resultados mostraron que se presentó inhibición de germinación para todas las especies estudiadas en las diferentes concentraciones. Así mismo al evaluar el efecto de los extractos sobre plántulas germinadas de las mismas especies de arvenses se observó fitotoxicidad en un alto grado. Igualmente, para determinar el efecto inhibitorio de dos extractos vegetales proveniente de Swinglia glutinosa y Lantana camara, Cuevas (2007) realizo ensayos de pre-emergencia y postemergencia, con aplicaciones de siete concentraciones $(0,500,1000,1500,2000,3000$ y $5000 \mathrm{mg} \mathrm{L}$, en las arvenses chilinchil (Senna obtusifolia), bledo (Amarantus dubius), lenguevaca (Rumexcrispus), gualola (Polygonum segetum) y nabo (Brassica rapa) y cinco de cultivos comerciales (arroz, maíz, zanahoria, lechuga y tomate). En los ensayos de preemergencia se observó que el extracto de $\mathrm{S}$. glutinosa inhibió la germinación y disminuyó la longitud radicular de las arvenses, cuando se aplicó a las semillas con la concentración más baja (500 mg L $\mathrm{L}^{1}$ ). Para los extractos de Lantana camara, se requirió de una dosis media de 2000 mg L' para observar el efecto de control en las variables evaluadas. No se observó un efecto deletéreo al realizar la aplicación a las semillas de cultivos comerciales, por lo que se podrían adoptar como mecanismos de control de malezas en pre-emergencia.

Chávez y Pérez (2008) evaluaron el efecto de seis extractos de Piperaceae (fruto y madera de Piper aduncum, hojas y raíz de Piper hispidium, parte aérea de Piper holtonii y madera de Piper eriopodon) sobre la germinación y el desarrollo de plántulas de caminadora (Rotboellia cochichinensis), sorguillo (Sorghum halepense), nabo (Brassica rapa), frijolillo (Phaseolus lathyroides), bledo (Amaranthus dubius) y lenguevaca (Rumex crispus). También se evaluaron estos extractos en semillas de cultivos que pueden indicar fitotoxicidad como maíz, arroz, lechuga, tomate y zanahoria. Los principales resultados indicaron que los diferentes extractos en las diferentes concentraciones inhibieron la germinación en las arvenses, principalmente frijolillo, caminadora y lenguevaca, sobresaliendo los extractos de madera de $P$. adumcum y raíz $P$. hispidium en concentración de 3000 mg LL. Igualmente, estos extractos produjeron reducciones fuertes en el desarrollo radicular y en la parte aérea de las arvenses y las plantas de cultivo como consecuencia de la aplicación.

\section{CONTROL DE INSECTOS-PLAGAS}

Las plantas han evolucionado por más de 400 millones de años, y para contrarrestar el ataque de los insectos han desarrollado mecanismos de protección como la repelencia y la acción insecticida (Silva et al., 2002). Después de la segunda guerra mundial, las pocas plantas que mostraban resultados auspiciosos como insecticidas naturales, alcanzaron a usarse masivamente pero fueron reemplazados por los insecticidas sintéticos. Con la aparición en la década de los cuarenta de estos insecticidas sintéticos, se pensó que los insecticidas vegetales desaparecerían para siempre pero problemas como la contaminación del ambiente, los residuos en los alimentos y la resistencia por parte de los insectos han hecho que hoy en día vuelvan a ser tomados en cuenta.

Sin lugar a dudas los fitoinsecticidas constituyen una muy interesante alternativa de control de insectos además de que sólo se han evaluado muy pocas plantas de las 250.000 que existen en el planeta, por lo que las perspectivas futuras son aun insospechadas. Existen plantas como el neem (Azadirachta indica; Meliaceae) que han mostrado tener excelentes resultados encontrándose ya en el mercado formulaciones comerciales. Estos constituyen una alternativa dentro de un programa de Manejo Integrado de Plagas que debe ser complementada con todas las otras medidas de control que existen (Silva et al., 2002).

Numerosos compuestos químicos se producen naturalmente y funcionan en algún grado como insecticidas. El rango de su efecto protector va desde repelencia, disuasión de la alimentación y oviposición, hasta toxicidad aguda e interferencia con el crecimiento y desarrollo de los insectos. Los insecticidas vegetales presentan la gran ventaja 
de ser compatibles con otras opciones de bajo riesgo aceptables en el control de insectos como feromonas, aceites, jabones, hongos entomopatógenos, depredadores y parasitoides, lo que aumenta enormemente sus posibilidades de integración a un programa de manejo integrado de plagas (MIP) (Malina, 2001).

Scorsetti y López (2007) reportaron por primera vez en la Argentina la presencia del hongo entomopatógeno Neozygites cf. floridana (Zygomycota: Zygomycetes: Entomophthorales) como patógeno de Tetranychus urticae (Acari: Tetranychidae), importante plaga de cultivos hortícolas. Los muestreos fueron realizados en el cinturón hortícola del Gran Río de La Plata sobre cultivos de tomate, pimiento, berenjena y otras hortalizas. Algunos compuestos volátiles parecen ser comunes a muchas especies, encontrándose entre ellos aldehídos, alcoholes, ésteres y terpenoides. Otros compuestos fitoquímicos tienden a ser, por lo contrario, específicos de cada especie; los hay que sirven para atraer depredadores y parásitos que destruyen a los herbívoros agresores, en otras palabras, ciertas especies vegetales reclaman la ayuda de otros artrópodos. En algunos casos más complejos, la porción de ácido graso de ciertos compuestos, como la volicitina, sufre una modificación en el intestino de los insectos que termina en la emisión de compuestos volátiles, éstos atraen parásitos del insecto y por tanto defienden a la planta (Vivanco et al., 2005). Muchas familias de plantas como las Myrtaceae, Asteraceae y Piperaceae son bien conocidas por tener principios como los terpenoides y grupos de amidas que tienen efecto antialimentario, repelente e insecticida que inhibe el desarrollo y el crecimiento de muchos insectos del orden Lepidóptera (Srivastava eta!., 2001).

Flórez (2003) estudió el efecto fagodisuasivo y posible ovidisuasivo de cuatro fracciones (acuosa, metanol: agua, metanólica y etérea) de madero negro (Gliricidia sepium, Fabácea), hombre grande (Quassia amara, Simarubaceae) y tacaco cimarrón (Sechium pittieri, Cucurbitácea), así como de 19 sustancias puras de origen vegetal, sobre los adultos de Bemisia tabaci, en condiciones de invernadero. Varias fracciones de los tres extractos vegetales poseen sustancias que pueden causar fagodisuasión (y posiblemente ovidisuasión), sobresaliendo la fracción metanólica en G. sepium y en Q. amara, así como la fracción acuosa de S. pittieri, las cuales causaron fagodisuasión a dosis bajas (10, 100 y 500 mg LL). Asimismo, algunas de las sustancias puras pueden causar repelencia en adultos de B. tabaci, entre las que sobresalió el cinamaldehído. Fazolin et al. (2002) evaluaron el efecto insecticida de extractos acuosos $y$ etanólicos de varias partes de plantas de 13 especies nativas provenientes de la Amazonia Brasilera, sobre adultos de Ceratoma tingomarianus. Los extractos fueron utilizados en varias formas de preparación y aplicados sobre plantas de fríjol (Phaseolus vulgaris). Los parámetros evaluados fueron efecto deterrente para alimentación y mortalidad. La rotenona en una concentración de 130 mg L L mostró ser promisoria para el control del insecto ya que además de causar mortalidad del $26.8 \%$ del adulto también presento efecto deterrente en la alimentación. El aceite de andiroba (Carapa guianensis) en concentraciones de 1000 y 1500 mg $L$ L , raíces en infusión de $P$. al/iaceae en concentración $2000 \mathrm{mg}$ L $\leftarrow$ y semillas de neem (Azadirachta indica) en concentración de 2000 mg L-1 mostraron efecto deterrente en alimentación de Ceratoma tingomarianus pero no causaron mortalidad.

Soberon et al. (2006) evaluaron la acción insecticida de extractos de Piper tuberculatum sobre larvas de Diatrea saccharalis. En el estudio utilizaron extractos acuosos, en diclorometanometanol y etanólico de hojas, tallos y espigas maduras, sobre larvas del tercer estadio. Los extractos de diclorometano-metanol y etanólico de espigas maduras y extracto de diclorometanometanol de plantas in vitro mostraron niveles significativos de mortalidad larval. Bogorni y Vendramim (2005) evaluaron el efecto de extractos acuosos de hojas y ramas de seis especies de Trichilia ( $T$. casaretti, $T$. catigua, $T$. c/ausseni, T.elegans, T. pal/ens y T. pal/ida)sobre el desarrollo de Spodoptera frugiperda bajo condiciones de laboratorio. Las hojas de sorgo fueron colocadas en una solución del 1000 mg LI 
se les elimino el exceso del extracto y después se colocaron sobre ellas larvas en primer instar de $\mathrm{S}$. frugiperda en condiciones de laboratorio. Se evaluaron los efectos de sobrevivencia, duración y peso de larvas y pupas. Los extractos de ramas de T. palida y de hojas de T. pallens fueron los más eficientes, dentro de las seis especies evaluadas, los demás extractos también mostraron efectos pero inferiores sobre el desarrollo de las larvas. Lizarazo et al. (2008) estudiaron el efecto de diferentes dosis de extractos acuosos, etanólicos y de diclorometano de hojas de carbonero (Calliandria pittieri), hierba mora (Solanum nigrum) y barbasco (Po/ygonum hydropiperoides) encontrando que el extracto de $P$. hydropiperoides obtenido con diclorometano produjo un efecto antialimentario e insecticida tipo Knock down de importancia económica en larvas de Spodoptera frugiperda criadas en condiciones de laboratorio. Murcia y Bermúdez (2008) evaluaron 10 tipos de extractos vegetales de diferentes especies de la familia Piperaceae para determinar su efecto insecticida sobre Spodoptera frugiperda mediante ensayos en condiciones semicontroladas en casa de malla utilizando dos dietas para determinar posible efecto insecticida de tipo fulminante $y / 0$ antialimentario. Las larvas de segundo y tercer instar fueron tratadas con extractos de Piper $s p$. en tres concentraciones (50, 100 y $150 \mathrm{mg} \mathrm{L}$, más tres testigos: absoluto, químico comercial (clorpiriphos) y biológico (Bacillus thurigiensis). A las 72 horas post-aplicación, ningún extracto produjo efecto fulminante sobre larvas. Los 10 extractos de Pipersp. evaluados mostraron efecto antialimentario, sobresaliendo $P$. eriopodon madera, $P$ holtonii, $P$. subtomentosum y $P$. aduncum inflorescencia; el extracto de madera de $P$. eriopodon $\left(50\right.$ y $100 \mathrm{mg} \quad \mathrm{L}^{-}, \mathrm{y} \quad P$. subtomentosum (150 y $50 \mathrm{mg} \mathrm{L}$ ) presentaron mayor efecto antialimentario y porcentajes altos de mortalidad similares a los testigo comerciales (clorpiriphos y $B$. thuringiensis). Pavela et al. (2008) realizaron estudios en laboratorio para determinar los efectos de extractos metanólicos de tres especies de Reynoturia sobre alimentación, el crecimiento y la mortalidad de larvas de Spodoptera littoralis. Ninguno de los extractos de las especies de Reynoturia mostró disuasión alimentaria en las larvas de S. littoralis; sin embargo, sí provocaron una disminución significativa en el crecimiento de larvas, así como en la eficiencia de conversión del alimento ingerido y digerido. La conversión de alimento ingerido fue menor comparada con las larvas testigo y el uso de alimento ocasionó prolongación del crecimiento de larvas así como toxicidad crónica. Aunque los extractos de las tres especies de plantas afectaron la mortalidad de las larvas de manera similar $\left(\mathrm{CL}_{50}\right.$-concentración letal media- varió entre 0,5 y 1,0 mg gen todos los extractos), el impacto en la inhibición del crecimiento de las larvas varió.

Las plantas con actividad insecticida constituyen un importante componente del manejo integrado de plagas. Bajo esta premisa, Pérez y lannaconne (2008) efectuaron un estudio para evaluar la mortalidad y repelencia larval de Eupalamides cyparissias. (Lepidoptera: Castniidae), plaga de la palma de aceite Elaeis guineensis, empleando las plantas con potencial insecticida ucullucuysacha (Heliotropium indicum, Boraginaceae), floripondio (Brugmansia $x$ candida, Solanaceae), oreja de tigre (Tradescantia zebrina, Commelinaceae), piñón blanco (Jathropa curcas, Euphorbiaceae), sacha yoco (Paullinia clavigera, Sapindaceae), yuquilla (Euphorbia cotinifolia, Euphorbiaceae), achiote (Bixa ore/lana, Bixaceae), caña fistula (Cassia fistula, Fabaceae), huancahuisacha (Aristolochia pilosa, Aristolochiaceae) y curare (Chondrodendron tomentosum, Menispermaceae). Los bioensayos con $E$. cyparissias abarcaron entre una hora y 24 horas bajo condiciones estandardizadas de laboratorio. A 24 horas de exposición, los mayores porcentajes de mortalidad de E. cyparissias se presentaron en los tratamientos con sacha yeco (63,3\% corteza y hojas en decocción), achiote (63,3 \% semillas en licuado) y yuquilla (48,3\% hojas en licuado). En el caso de la repelencia, los mayores efectos se encontraron en los tratamientos con achiote $(83,30 \%)$, sacha yeco (75\%) y floripondio (66,7\% hojas en licuado). Torres y Pachón (2008) evaluaron el efecto insecticida y antialimentario de los extractos vegetales de barbasco (Polygonum hydropiperoides) y especies del género Piper 
adumcum (hoja y madera) sobre Schizomya $s p$. La aplicación de extractos se realizó sobre larvas en primer instar, criadas en una dieta artificial basada en una solución nutritiva de botones florales de tomate de árbol y agar. Los resultados mostraron que la aplicación del extracto etanólico de barbasco ( $P$. hydropiperoides), en sus diferentes concentraciones $(1000,2000$ y 3000 mg LL, causó una mortalidad del $100 \%$ a las 96 horas después de la aplicación y un efecto antialimentario del 4\%. Estos resultados sugieren que la aplicación de los diferentes extractos permite controlar con una mortalidad del $100 \%$ las larvas de Schizomya sp.

Hincapié et al. (2008) evaluaron el efecto insecticida de extractos de semilla de Annona muricata. Los extractos fueron obtenidos con hexano (apelar), acetato de etilo (medianamente polar) y etanol (polar), y fueron aplicados sobre adultos de Sitophyl/us zeamais, por medio de ingestión y aplicación topical. También se evaluó la emergencia de nuevos adultos en semillas de maíz tratadas con los mismos extractos. La $\mathrm{CL}_{50}$ obtenida en los bioensayos de ingestión para el extracto hexánico fue de 4009, 3854 y 3760 mg L1 a las 24,48 y 72 horas, respectivamente. Para el extracto obtenido con acetato de etilo fue de 3280, 2667 y 2542 mg L'en los mismos tiempos. La $\mathrm{CL}_{50}$ del extracto hexánico en aplicación topical fue de $9368 \mathrm{mg}$ L'a las 72 horas. Los demás extractos en ambos bioensayos presentaron muy poca actividad. La emergencia se inhibió en 100\% a partir de las concentraciones de $2500 \mathrm{mg} \mathrm{L}$ para los extractos obtenidos con acetato de etilo y hexano y de $5000 \mathrm{mg} \mathrm{L'}$ para los obtenidos con alcohol etílico. Los extractos fueron más efectivos por ingestión que por contacto y se cree que el efecto insecticida es causado probablemente por la presencia de acetogeninas en las fracciones menos polares de la semilla de $A$. muricata.

\section{CONTROL DE ENFERMEDADES}

El control biológico de enfermedades de plantas constituye una práctica ampliamente difundida y sigue siendo objeto de investigación y desarrollo. Un concepto amplio de control biológico incluye nociones como las de prácticas de cultivo y resistencia a las enfermedades. Desde esta perspectiva se acepta que es "la reducción de la cantidad del inoculo o en la actividad en la producción de la enfermedad producida por un patógeno o parásito en su estado activo o latente, por acción de uno o más organismos, efectuado naturalmente o por medio de la manipulación del ambiente, del huésped o del antagonista, o por la inducción de uno o más antagonistas" (Izquierdo et al., 1995). Por otra parte, se encuentra el concepto clásico que se restringe a que control biológico es el uso deliberado de un organismo para controlar a otro. Sin embargo, y en relación a este último concepto, es necesario considerar que las interacciones de múltiples variables presentes en el medio ambiente pueden modificar las interacciones entre los microorganismos y su entorno, muchas de las cuáles pueden favorecer o impedir un control biológico efectivo (McSpaddenGardener, 2002).

El genero Trichoderma hace parte de un pequeño grupo de hongos benéficos, los cuales son considerados como agentes de control biológico. Su actividad es parasítica a través de la supervivencia sobre el hongo patógeno. Trichoderma está registrado como un biofungicida en países como Francia, el Reino Unido, Suiza, Bélgica, Chile, Nueva Zelanda y Estados Unidos, y esta pendiente su registro en muchos otros países (Sait, 2000). El hongo Trichoderma puede inhibir a los patógenos por medio de antibióticos o degradando las paredes celulares a través de enzimas tales como las quitinasas, 1,3glucanasas, proteasas, mannasas y otras hydrolasas (Limón et al., 1999). Además es completamente inocuo para los humanos; en 55 años de investigación con este hongo, nunca se ha reportado causando reacciones tóxicas (Sait, 2000).

Con el objeto de buscar alternativas naturales para el control de enfermedades en plantas, Zapata et al. (2003) hicieron extracciones etanólicas desgrasadas (EED), etanólicas sin desgrasar (EESD) y acuosas (EA) de secciones medias del tallo de Cereus deficiens (Cactaceae) colectados en El Tocuyo, estado Lara, Venezuela. Determinaron cualitativamente la presencia de metabolitos secundarios en el EED y se evaluó el efecto de los extractos sobre el desarrollo in vitre de 10 hongos fitopatógenos crecidos en papadextrosa-agar con $0,25,50$ y $75 \%$ de los extractos. Los resultados indicaron la presencia 
de aceites esenciales, polifenoles, taninos y saponinas, y adicionalmente se encontró un efecto significativo $(\operatorname{Pr}<0,001)$ de los extractos sobre la reducción del crecimiento micelial de todos los patógenos evaluados, especialmente de Phytophthora infestans y Sclerotium rolfsii, donde se obtuvieron reducciones de 70 a $94 \%$ en el crecimiento micelial; el mayor efecto lo mostraron EED y EESD. El estudio mostró que el efecto reductor de los extractos fue directamente proporcional a la concentración utilizada.

Puente et al. (2005) sostiene que el uso indiscriminado de pesticidas en las prácticas agrícolas ha causado contaminación ambiental, problemas a la salud humana y productos agrícolas inseguros. Por tal motivo, implementaron un trabajo en condiciones de campo con el objetivo de evaluar el efecto del extracto vegetal al $50 \%$ de concentración de Phyla strigullosa var serícea, sobre el hongo fitopatógeno del suelo Sclerotium rolfsii Sacc., causante de pudriciones en el cuello y raíz de plántulas de cultivos susceptibles. Los resultados mostraron mostraron actividad inhibitoria de los extractos sobre el hongo y su potencial como especie alelopática. Un análisis de los extractos evaluados demostró que contienen flavonoides, fenoles, taninos, aminoácidos, saponinas, quinonas y alcaloides. La inhibición del crecimiento micelial exhibida por los extractos se debe a la presencia de algunos de estos metabolitos, como los flavonoides que son un grupo de compuestos de amplio rango de actividad biológica. Lizcano (2007) evaluó la actividad antifúngica del extracto de tomillo (Thymus vulgaris) sobre los hongos Fusarium oxysporum, Botrytis cirenea y Sclerotinia sclerotiorum. La dosis más efectiva fue $500 \mathrm{~g} \mathrm{~L}^{-1}$.

Hernández y Vásquez (2007), determinaron que la aplicación de extractos vegetales de hojas de Piper aduncum y Thymus vulgaris, y flores de Matricharia chamomilla, permite controlar bajo condiciones in vitro y en plántulas, el desarrollo del hongo Colletotrichum gloeosporoides, causante de la antracnosis en tomate de árbol. Los resultados obtenidos en este estudio, determinaron que el mayor control del hongo se obtuvo con el extracto floral de M. chamomilla. Debido a la actividad biológica de la familia Piperaceae, los autores sugieren realizar estudios para determinar si existe una mayor inhibición de C. gloeosporoides con extractos de inflorescencias de $P$. aduncum, debida a la presencia de lignanos y flavonoides. Pruebas realizadas en los últimos años con el fin de verificar la eficacia de algunos productos de origen natural en rosas cultivadas fuera del suelo e inoculadas naturalmente permitieron observar que la disponibilidad de nuevos productos utilizables en el control del oídio de la rosa está en una fase de progreso. Resultados obtenidos con extracto de Piper nigrum y la mezcla de dos aceites vegetales desarrollaron una suficiente protección. La actividad antifúngica del derivado de la pimienta negra parece ligada a las amidas (Passini et al., 2004). Para el control de la antracnosis del fríjol (Phaseolus vulgaris L.) en invernadero y campo, Salgado-Garciglia et al. (2008) evaluaron el efecto del extracto crudo (EC) y la mezcla de compuestos bioactivos afinina (A) y decatrién bornilo (DB), obtenidos de la raíz de Heliopsis longipes 'A. Gray' Blake; también se evaluó el efecto sobre la colonización de la raíz del fríjol por hongos micorrízicos vesículo arbusculares (HMVA) y la nodulación de bacterias fijadoras de nitrógeno. Dos de las concentraciones del EC $\left(700 / 70\right.$ y $\left.70 / 7 \mu \mathrm{g} \mathrm{ml}^{-1}\right)$ y A/DB (700/70 y 70/7 $\mu \mathrm{g} \mathrm{ml}^{-1}$ ) redujeron la incidencia de la antracnosis en $90 \%$ sin reducción significativa $(\operatorname{Pr}>0,05)$ del peso seco de las plantas tratadas en invernadero; mientras que en campo, las concentraciones evaluadas de EC $\left(70 / 7 \mu \mathrm{g} \mathrm{ml}^{-1}\right)$ y $\mathrm{A} / \mathrm{DB}\left(70 / 7 \mu \mathrm{g} \mathrm{ml}^{-1}\right)$ redujeron la incidencia de la antracnosis en $88 \%$, sin efecto significativo sobre el peso seco de las plantas tratadas $(\operatorname{Pr}>0,05)$, lo que confirmó la capacidad de estos compuestos para reducir los efectos de la enfermedad. La aplicación del EC y la mezcla A/DB en campo no afectó el establecimiento de HMVA y bacterias fijadoras de nitrógeno en las raíces de fríjol. Carvalho et al. (2008) evaluaron el efecto fungitoxico de extractos de Cymbopogon citratus y Cymbopogon martinii sobre Colletotrichum gloeosporioides en frutos de pimentón para buscar alternativas de control de esta enfermedad. Los resultados de la evaluación in vitro al utilizar concentraciones del de 1, 5, 10, $15,20,25$ y $50 \%$ incorporados al medio PDA no inhibieron el crecimiento micelial, la esporulación y la germinación de esporas pero si tuvieron efecto inhibitorio sobre formación de apresorios. 


\section{CONCLUSIÓN}

A partir de los resultados anteriormente expuestos se sugiere que es necesario desarrollar un sistema de manejo integrado de plagas, enfermedades y arvenses basado en la utilización de productos naturales de plantas, que reduzcan la dependencia de los productos de síntesis química y por tanto produzcan menos contaminación ambiental y mayor calidad en los alimentos agrícolas producidos.

\section{BIBLIOGRAFIA}

Alfonso, M.; Villasana, R.; Lorenzo, Y.; Álvarez M.; Pérez D. y Uranga H. 2005. Análisis fitoquímico de cinco plantas con actividad alelopática. Memorias XVII Congreso de la Asociación Latinoamericana de Malezas (ALAM). Varadero, Matanzas, p. 592 595.

Bogorni, P. y Vendramim, J. 2005. Efeito subletal de extratos aquosos de Trichilia spp. sobre - desenvolvimento de Spodoptera frugiperda (J.E. Smith) (Lepidoptera: Noctuidae) em Milho. Neotropical Entomology 34(2):311-317.

Carvalho, J.; Schwan-Estrada, K.; Bonaldo, S.; Cruz; M.; Carlos, M. y Stangarlin, J. 2008. Fungitoxicida de Cymbopogon citratus e Cymbopogon martinii a Colletotrichum g/oeosporioides em frutos de pimentao. Revista Brasileira de Plantas Medicas 10(1):88-93.

Catasus, L. 1997. Manual de Agrostología. Editorial Academia, La Habana, 98p.

Celis, A.; Mendoza, C.; Pachon, M.; Cardona, J.; Delgado, W. y Cuca, E. 2008. Extractos vegetales utilizados como biocontroladores con énfasis en la familia piperaceae, Una revisión. Agronomía Colombiana 26(1):97-106.

Chávez, D. y Pérez, Y. 2008. Efectos alelopáticos de extractos de piperaceae sobre germinación y emergencia de arvenses y plantas cultivadas bajo condiciones controladas Tesis Ingeniero Agrónomo, Universidad de Cundinamarca, Fusagasugá.
Cock, M. 1986. Biological control of weeds in tropical crops. En: Hussain, M. y Ibrahim, A. (Ed.) Biological Control in the Tropics. Proceedings of the First Regional Symposium on Biological Control, University Pertanian Malaysia, Serdang, Kuala Lumpur, p375-385.

Cuevas, J. 2007. Aspectos fisiológicos en el proceso germinativo de especies de arvenses y plantas de cultivo y el efecto inhibitorio producido por extractos de Swinglia glutinosa Murray y Lantana camara L. Tesis Ingeniero Agrónomo, Universidad de Cundinamarca, Fusagasugá.

Díaz, C. y Pérez, E. 2005. Manejo integrado de malezas en cultivos económicos principales. Memorias XVII Congreso de la Asociación Latinoamericana de Malezas (ALAM), Varadero, p153-170.

Fazolin, M.; Lima, J. y Pereira, A. 2002. Avaliac;ao de plantas com potencial inseticida No controle la vaquinha do feijoleiro (Ceratoma tingomarianus) Bechine. Boletim do Pesquisa e Desenvolvimiento, Embrapa, Ria Branca, 37:37.

Flórez, G. 2003. Evaluación de fracciones de extractos y de sustancias puras de origen vegetal como disuasivos o repelentes de adultos de Bemisia tabaci. Tesis Postgrado enEducación, CATIE, San José.

Grainge, M. y Ahmeds, A. 1988. Handbook of Plant with Pest Control Properties. John Wiley and Sons, New York, $470 \mathrm{p}$. 
TEMAS AGRARIOS 14(1): 5-16 ENERO - JUNIO DE 2009

Hernández, E. y Vázquez, J. 2007. Evaluación de tres extractos vegetales para el control de antracnosis (Colletotrichum gloeosporoides (Penz \& Sacc.) en tomate de árbol (Cyphomandra betaceae (Cav.) Sendt). Tesis Ingeniero Agrónomo, Universidad de Cundinamarca, Fusagasugá.

Hincapié., C.; Lopera, D. y Ceballos, M. 2008. Actividad insecticida de extractos de semilla de Annona muricata (Anonácea) sobre Sitophilus zeamais (Coleoptera: Curculionidae). Revista Colombiana de Entomología 34(1):76-82.

Izquierdo, J.; Ciampi, L. y García, E. 1995. Biotecnología apropiable: racionalidad de su desarrollo y aplicación en América Latina y el Caribe. Oficina regional de la FAO para América Latina y el Caribe. Santiago. http://www.rlc.fao.org/prior/se galim/proda lim/prodveg/aprop.pdf. [Accedido: 15-03-2007].

Kagale, S.; Marimuthu, T.; Thayumanavan, B.; Nandakuman, R. y Samiyappan, R. 2004. Antimicrobial activity and induction of systemic resistance in rice by leaf extract of Datura mete/against Rhizoctonia solani and Xanthomonas oryzae pv. Oryzae. Physiological and Molecular Plant Pathology 65(2):91-100.

Labrada, R. 2003. El control de malezas en el contexto del Manejo Integrado de Plagas. En: Labrada, R.; Caseley, J. y Parker, C. (Ed). Manejo de Malezas para Países en Desarrollo. Producción y Protección Vegetal, FAO, Roma, p3-9.

Limón, M.; Pintor-Toro, A. y Benítez, T. 1999. Increased antifungal activity of Trichoderma harzianum transformants that overexpress a $33 \mathrm{KDa}$ chitinase. Phytopathology 89:254-261.

Lizarazo, K.; Mendoza, C. y Carrero, R. 2008. Efecto de extractos vegetales Polygonum hydropiperoides, Solanum nigrum y Calliandra pittieri sobre el gusano cogollero (Spodoptera frugiperda). Revista Agronomía Colombiana 26 (3):427-434.
Lizcano, M. 2007. Evaluación de la actividad fungicida del extracto de tomillo (Thymus vu/garis) contra Fusarium oxysporum y Sclerotinia sclerotiorum, Tesis Microbiólogo Agrícola y Veterinario, Pontificia Universidad Javeriana, Bogotá.

Mcspadden-Gardener, B. y Fravel, D. 2002. Biological control of plant pathogens: Research, commercia lization and application in the USA. http://www.apsnet.org/online/feature/bio control/top.html. [Accedido: 12-02-2009].

Miquilena, M. y Lazo, L. 2005. Evaluación del potencial alelopático de lavados foliares de Echinoch/oa colona (1) Link sobre especies cultivadas ubicadas en agroecosistemas de los estados Falcón y Aragua, (Venezuela). Memorias XVII Congreso de la Asociación Latinoamericana de Malezas (ALAM). Varadero, Matanzas, p625-630.

Melina, N. 2001. Uso de extractos botánicos en el control de plagas y enfermedades. Avances en el fomento de productos fitosanitarios no sintéticos. Manejo Integrado de Plagas. CATIE, San José, 59:56-59.

Murcia, A. y Bermúdez, H. 2008. Evaluación de la actividad insecticida de extractos vegetales de la familia piperaceae, sobre Spodoptera frugiperda Smith, en condiciones semicontroladas. Tesis Ingeniero Agrónomo, Universidad de Cundinamarca, Fusagasugá.

Obledo, E.; Hernández-Rosales, S. y López, M. 2004. Extractos vegetales, una opción en el control de la Sigatoka negra. XVI Reunión Internacional ACORBAT. Oaxaca, p184.

Pasini, C.; Sacco, M.; Curir, P. y D'Aquila, F. 2004. Defensa de especies ornamentales con productos naturales y organismos auxiliares: Recientes experiencias en Sanremo (Italia) CRA- Istituto Sperimentale per la Floricoltura, Sezione di Biologia e Difesa. Sanremo 508:18038. 
Pavela, R.; Vrchotová, N. y Bozena, S. 2008. Efecto inhibitorio del crecimiento de los extractos de plantas de Reynoutria $s p$. contra larvas de Spodoptera littoralis. Agrociencia 42(5): 573-584.

Pérez, D. y lannaconne, O. 2008. Mortalidad y repelencia en Eupa/amides cyparissias (Lepidoptera: Castniidae), plaga de la palma aceitera Elaeis guineensis, por efecto de diez extractos botánicos. Revista de la Sociedad de Entomología de Argentina 67(1):41-48.

Philogene, B.; Regnault-Roger, C. y Vincent C. 2004. Productos fitosanitarios insecticidas de origen vegetal: promesas de ayer y de hoy. En: Regnault-Roger, C.; Philogene, B. y Vincent, $C,(E d)$. Biopesticidas de Origen Vegetal. Ediciones Mundi Prensa, Madrid, pl-18.

Puente, M.; Campos, A. y León, A. 2005. Efecto fungicida o fungistático de un extracto vegetal sobre plantas susceptibles al hongo fitopatógeno del suelo Sclerotium rolfsii Sacc. en condiciones de cultivo protegido. Memorias XVII Congreso de la Asociación Latinoamericana de Malezas (ALAM). Varadero, Matanzas, p637-643.

Putman, A. 1985. Weed allelopathy. En: Duke, S. (Ed). Weed Physiology. Vol 1. Reproduction and Ecophysiology. CRC Press, Boca Raton, p131-155.

Regnault-Roger, C. 2004. Nuevos insecticidas para el tercer milenio. En: Biopesticidas de origen vegetal. En: Regnault-Roger, C.; Philogene, B. y Vincent, C, (Ed). Ediciones Mundiprensa, Madrid, p19-40.

Rice, E. 1984. Allelopathy. Academic Press, Nueva York, 422 p.

Robayo, D. y Rodríguez, Y. 2006. Determinación de la actividad alelopática de extractos de Swinqlia qlutinosa Murray y Piper aduncum L., sobre germinación de semillas de arvenses. Tesis Ingeniero Agrónomo, Universidad de Cundinamarca, Fusagasugá.
Sait, G. 2000. Trichoderma - A promising BioFungicide. Nutri-Tech Solutions, New Zealand, p4-20.

Salgado-Garciglia, R.; Malina, J.; López, J. y Loeza, P. 2008. Efecto del extracto crudo y los compuestos bioactivos de Heliopsis longipes sobre la incidencia de la antracnosis, micorrización y nodulación del fríjol. Agrociencia 42(6): 679-688.

Scorsetti, A. y López, C. 2007. Primer registro del hongo Neozygites sp. (Zygomycota: Entomophthorales), patógeno de Tetranychus urticae (Acari: Tetranychidae) en la República Argentina Córdoba, Argentina. Boletín Sociedad Argentina de Botánica 42:3-4.

Silva, G.; Lagunes, A.; Rodríguez, J. y Rodríguez, D. 2002. Insecticidas Vegetales: Una vieja-nueva alternativa en el control de plagas. Revista Manejo Integrado de Plagas 66:4-12.

Soberón, G.; Rojas, C.; Saavedra, J.; Kato, M. y Delgado, G. 2006. Acción biocida de plantas de Piper tuberculatum Jacq. sobre Diatrea saccharalis (Lepidoptera, Pyralidae). Revista Peruana de Biología 13(1):197-112.

Srivastava, S.; Gupta, M.; Prajapati, V.; Tripathi, A. y Kumar, S. 2001. Insecticida! activity of myristicin from Piper mullesua. Pharmaceutical Biology 39(3): 226.

Torres, T. y Pachón, R. 2008. Evaluación de tres extractos vegetales sobre larvas de liberalito (Schizomya sp) en primer instar en cultivo de tomate de árbol (Cyphomandra betacea Send) en condiciones de laboratorio. Tesis Ingeniero Agrónomo, Universidad de Cundinamarca, Fusagasugá.

Valerino, A.; González, T. y Spengler, I. 2005. Estudio fitoquímico biodirigido de la actividad alelopática del follaje de Lantana trifolia L. Parte I. Memorias XVII Congreso de la Asociación Latinoamericana de Malezas (ALAM). Varadero, Matanzas, p652-660. 
Vivanco, J.; Cesio, E.; Loyola, V. y Flórez, H. Zapata, R.; Sanabria, M. y Rodríguez, D. 2003. 2005. Mecanismos químicos de defensa en las plantas. Investigación y Ciencia, Prensa Científica S.A. Barcelona 341:3135. Reducción del desarrollo de hongos fitopatógenos con extracto de cardón Lefaria (Cereus deficiens Otto \& Diert). Interciencia 28(5):302 - 306. 